\title{
Studi Struktur Mikro dan Kuat Lentur Komposit Geopolimer Serat Bambu dengan Temperatur Curing Berbeda
}

\author{
Vicran Zharvan, Muris, dan Subaer* \\ Pusat Penelitian Geopolimer - Lab. Fisika Material, \\ Jurusan Fisika-FMIPA Universitas Negeri Makassar \\ Jl. Daeng Tata Raya, Makassar 90223
}

\begin{abstract}
Telah dilakukan studi struktur mikro dan kuat lentur komposit geopolimer berbahan dasar metakaolin dan penguat (agregat) serat bambu. Penelitian ini bertujuan untuk mengetahui nilai kuat lentur komposit geopolimer sebagai fungsi massa serat bambu $(0,4 \mathrm{~g}, 0,6 \mathrm{~g}$, dan $0,8 \mathrm{~g})$ serta suhu curing $\left(150,450\right.$ dan $\left.750^{\circ} \mathrm{C}\right)$. Komposit geopolimer serat bambu disentesis dengan metode alkali aktivasi metakaolin dengan model sandwich berbentuk persegi panjang dengan massa serat yang berbeda lalu di curing pada suhu $60^{\circ} \mathrm{C}$ selama 1 jam. Sampel selanjutnya di recurring masing-masing pada suhu 150,450 , dah $750^{\circ} \mathrm{C}$. Karakterisasi morfologi serta struktur kristal bahan dasar dan produk komposit geopolimer dilakukan dengan SEM dan XRD. Sifat termal serat bambu diukur menggunakan DSC. Hasil karakterisasi SEM menunjukkan ikatan antara matriks dengan serat bamboo belum sempurna akibat kehadiran celah yang cukup besar.Hasil karakterisasi dengan XRD memperlihatkan bahwa matriks geopolimer bersifat amorf. Uji mekanik berupa three bending points flexural strength yang dilakukan terhadap 3 sampel untuk setiap komposisi dan suhu curing menunjukkan kuat lentur tertinggi diperoleh dengan penambahan serat bambu sebesar $0.6 \mathrm{~g}$ ( $1.5 \%$ dari volume sampel) untuk setiap variasi suhucuring dengan nilai berturut-turut sebesar 665,90 \pm 98,40 KPa, 947,29 \pm 287,13 KPa dan 1155,62 \pm 98,30 KPa.
\end{abstract}

\section{ABSTRACT}

\begin{abstract}
Microstructure and flexural strength of composite-geopolymers based on metakaolin with bamboo fibers aggregate have been studied.The main objective of this study was to determine the flexural strength of compositegeopolymers as a function of bamboo fibers mass $(0.4 \mathrm{~g}, 0.6 \mathrm{~g}$, and $0.8 \mathrm{~g})$ as well as their curing temperatures $\left(150,450\right.$, dan $\left.750^{\circ} \mathrm{C}\right)$. Composite-geopolymers were synthesized by using alkali activation method of metakaolin and they were formed in rectangular sandwich shape by varying the mass of bamboo fibers and then cured at $60^{\circ} \mathrm{C}$ for 1 hour. The sample was then recurring at temperature of 150,450 , dah $750^{\circ} \mathrm{C}$, respectively. The morphology of the precursors and samples were examined by using SEM and XRD. Thermal properties of bamboo fibers were studied by using differential Perkin Elemer 400 differential scanning calorimetry (DSC). SEM characterization shows that the bond between the matrix of geopolymer and the aggregate is still weak due to the presence of appreciable wide gap. The matrix of geopolymer was amorf in nature based on XRD result. Three bending points flexural strength measurements on three samples for each composition and curing temperature showed that the highest flexural strength was achieved on fiber addition of $0.6 \mathrm{~g}(1.5 \%$ of sample volume) for all curing temperatures with magnitude of $665.90 \pm 98.40 \mathrm{KPa}, 947.29 \pm 287.13 \mathrm{KPa}$ dan 1155.62 $\pm 98.30 \mathrm{KPa}$.
\end{abstract}

KATA KUNCI: composite, geopolymer, flexural strength, cured, SEM and XRD

\section{PENDAHULUAN}

Perkembangan Ilmu Pengetahuan dan Teknologi (IPTEK) khususnya pada bidang material seperti komposit berlangsung sangat cepat. Secara umum, komposit merupakan penggabungan dua buah material atau lebih yang berbeda sifatnya menjadi sebuah material yang mempunyai sifat baru yang berbeda dari sifat material induknya.

Dewasa ini, aplikasi material komposit khususnya polimer

\footnotetext{
*E-MAIL: jzubayir@yahoo.com
}

komposit sebagai material rekayasa menempati posisi tertinggi. Untuk memperoleh komposit rekayasa yang bermutu tinggi, diperlukan desain baru dengan cara memilih komposisi dan cara pengerjaan yang tepat. Terdapat banyak kemungkinan untuk membuat komposit yang terdiri atas isian atau penguat yang berbeda.

Indonesia merupakan negara tropis yang tanahnya subur. Salah satu tumbuhan yang melimpah adalah bambu dengan serat yang mengandung selulosa. Selulosa dalam bambu berfungsi menjaga struktur dan kekakuan dari tanaman. Selain itu, serat selulosa merupakan serat yang paling banyak didapatkan pada kayu ataupun rerumputan. Serat ini memberikan keuntungan yang menarik seperti kerapatan yang ren- 
dah, mudah didaur ulang, dan ketersediannya melimpah. Keseluruhan sifat ini membuatnya menjadi material yang baik untuk penguat matriks, seperti komposit polimer atau aplikasi semen-serat [1].

Komposit merupakan gabungan dua bahan atau lebih yang berbeda sifatnya menjadi satu kesatuan yang menghasilkan material baru yang memiliki sifat berbeda dari material dasarnya. Secara umum, komposit terdiri atas matriks dan penguat.

Pada tingkat atom (struktur mikro), material seperti logam alloy dan polimer dapat disebut komposit karena terdiri atas kelompok atom yang berbeda. Pada tingkat atau struktur mikro, plastik yang diperkuat dengan serat-gelas (fiber-glass reinforced plastics) dapat disebut komposit (serat-gelas dapat dilihat jelas dengan mata). Dalam dunia industri, material yang disebut komposit umumnya terdiri atas campuran materi dengan ukuran rentang mikro hingga makro [2].

Matriks pada komposit merupakan material yang memiliki volume yang lebih banyak dibandingkan penguatnya. Dalam studi ini, komposit direkayasa dengan menggunakan pasta geopolimer berbahan dasar metakaolin sebagai matriks. Metakaolin merupakan mineral hasil dehidroksilasi kaolin pada temperatur $750^{\circ} \mathrm{C}$ selama 6 jam. Proses ini bertujuan untuk meruntuhkan gugus $(\mathrm{OH})$-mineral kaolin dan membuat metakaolin reaktif terhadap larutan alkali. Selain itu, sifat kekristalan dari mineral kaolin juga menghilang dikarenakan lapisan struktur heksagonal dari kaolin runtuh sebagian pada temperatur tersebut [3]. Reaksi eksotermal dari kaolin dapat dilihat pada persamaan berikut:

$$
2 \mathrm{Al}_{2} \mathrm{Si}_{2} \mathrm{O}_{5}(\mathrm{OH})_{4} \rightarrow 2 \mathrm{Al}_{2} \mathrm{Si}_{2} \mathrm{O}_{7}+4 \mathrm{H}_{2} \mathrm{O}
$$

Geopolimer dihasilkan melalui aktivasi alkali mineral. Rasio komposisi antara prekursor geopolimer dan larutan alkali sangat berperangaruh pada sifat mekanik material yang dihasilkan. Metakaolin sebagai hasil dehidroksilasi kaolin sangat reaktif terhadap larutan alkali.

Sebagai penguat untuk komposit, serat alam memiliki keunggulan antara lain sifatnya yang dapat diperbarui, dapat didaur ulang serta dapat terdegradasi di lingkungan [4]. Serat alam juga memiliki keunggulan pada sifat mekanik dan memiliki harga yang relatif murah dibandingkan serat sintetik. Namun, serat alam juga memiliki kelemahan terutama kemudahannya dalam menyerap air, kualitas yang tidak seragam, serta memiliki kestabilan yang rendah terhadap panas [5].

Bambu betung (dendrocalamus asper) adalah jenis bambu yang kuat, tingginya bisa mencapai 20-30 m dan diameter batang $8-20 \mathrm{~cm}$. Bambu jenis ini banyak digunakan untuk bahan bangunan rumah maupun jembatan. Komponen kimia yang terdapat pada bambu betung adalah holoselulosa 53\%, pentosan $19 \%$, lignin $25 \%$, abu $3 \%$ [6].

Komposit yang menggunakan serat harus memperhatikan beberapa faktor seperti faktor serat, panjang serat, letak serat, bentuk serat, faktor matriks, faktor ikatan antara serat dan matriks, void. Secara umum penguat yang berupa serat harus memiliki kekuatan yang tidak dimiliki oleh matriks sehingga keberadaaan serat dalam matriks mampu mentransferkan beban yang diterima oleh matriks dan komposit dapat bertahan dari pengaruh gaya dari luar.

\section{METODOLOGI}

Studi ini diarahkan pada pengembangan komposit geopolimer berbahan dasar kaolin dan penguat serat bambu. Mineral kaolin didehidroksilasi pada temperatur $750^{\circ} \mathrm{C}$ selama 6 jam dan menghasilkan fase metakaolin yang bersifat amorf.

Bambu yang digunakan merupakan jenis bambu betung yang berasal dari Kabupaten Bone. Untuk mendapatkan serat bambu, bambu terlebih dahulu dibersihkan dari kulit luarnya kemudian dipotong-potong sepanjang kira-kira $10 \mathrm{~cm}$. Bambu yang telah bersih tersebut selanjutnya dimasak selama 12 jam kemudian dikeringkan. Bambu yang telah kering selanjutnya diserut menggunakan pisau cutter sehingga diperoleh serat bambu. Hasil serutan selanjutnya direndam dengan lauran $\mathrm{NaOH}$ selama 1 jam. Setelah itu, serat bambu kemudian dicuci dengan $\mathrm{pH}$ netral lalu didiamkan selama 24 jam. Serat bambu hasil rendaman selanjutnya dibilas dengan $\mathrm{pH}$ netral hingga bersih lalu dikeringkan dan siap untuk digunakan.

Dalam pembuatan komposit, metakaolin diaktivasi dengan larutan alkali pada komposisi yang tepat sehingga diperoleh material gel yang homogen. Sebagaimana material tersebut dituang ke dalam cetakan yang berukuran $12,0 \times 3,0 \times 1,1$ $\mathrm{cm}^{3}$ lalu diisi dengan serat bambu yang berbentuk lempeng. Sisa material gel kembali dituangkan di atas serat hingga isi cetakan penuh.

Sampel kemudian di-curing pada temperatur $60^{\circ} \mathrm{C}$ selama 1 jam lalu didiamkan selama 28 hari. Setelah sampel berumur 28 hari, sampel kemudian di-curing pada temperatur berbeda yakni 150,450 dan $750^{\circ} \mathrm{C}$ selama 17 jam. Sampel lalu kembali didiamkan selama 7 hari. Setelah berumur 7 hari, sampel siap untuk dilakukan uji kelenturan dengan menggunakan metode three point bending test.

Sifat termal serat diukur dengan menggunakan DSC, untuk mengetahui morfologi permukaan sampel serta komposisi kimia (wt\% oksida) digunakan Tescan Vega3SB Analitical SEM-EDS (Scanning Electron Microscope-Energy Dispersive $X$-ray Spectroscopy). Struktur kekristalan serta fase yang dikandung sampel diuji dengan XRD.

\section{HASIL DAN DISKUSI}

\section{Karakterisasi bahan dasar}

Gambar 1(a) memperlihatkan morfologi kaolin yang digunakan. Ukuran dari partikel kaolin yang digunakan berkisar 5 $\mu \mathrm{m}$ berbentuk lempeng dan pipih.

Dari hasil pengukuran dengan EDS diperoleh komposisi utama penyusun kaolin seperti pada Tabel I. Pada Tabel I memperlihatkan perbandingan $\mathrm{Al}_{2} \mathrm{O}_{3}$ dan $\mathrm{SiO}_{2}$ mendekati 1 . Hal ini berkesesuaian dengan hasil yang diperoleh Zuhua [7] yang memperoleh nilai perbandingan ini sebesar 1,18 untuk kaolin yang berasal dari Cina. 


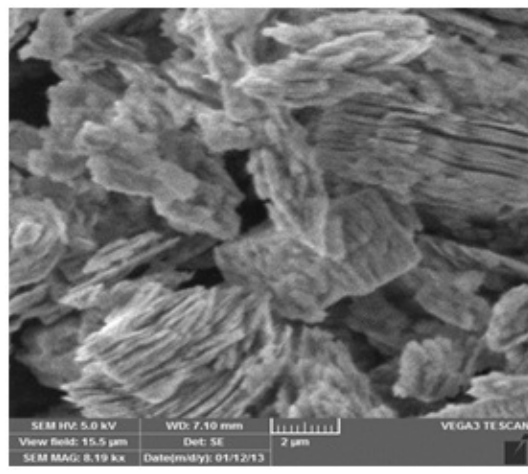

(a)

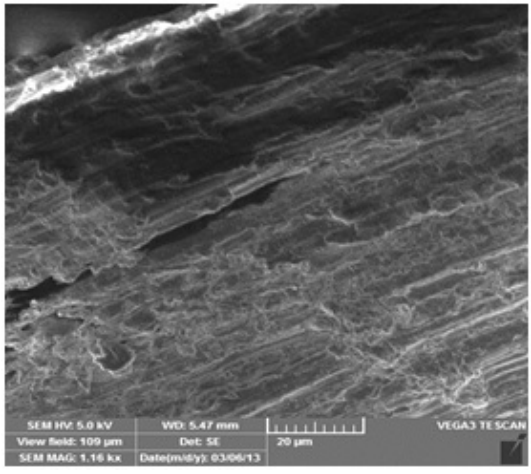

(b)

Gambar 1: Morfologi (a). mineral kaolin, (b). serat bambu.

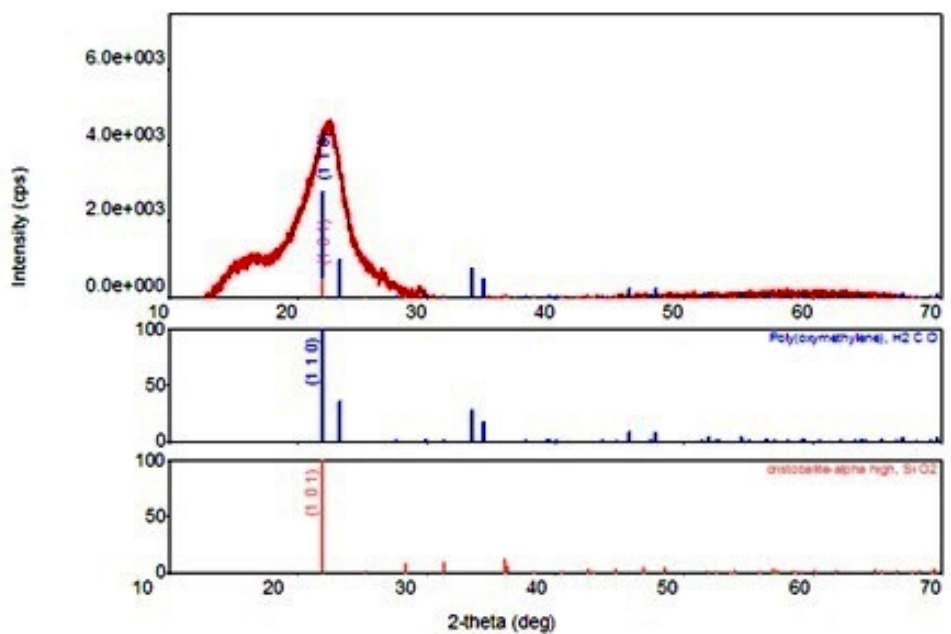

Gambar 2: Hasil analisis XRD serat bambu.

TABEL I: Hasil analisis EDS mineral kaolin pada Gambar 1(a)

\begin{tabular}{|c|c|}
\hline Komponen & wt (\%) \\
\hline $\mathrm{Al}_{2} \mathrm{O}_{3}$ & 49,68 \\
\hline $\mathrm{SiO}_{2}$ & 49,47 \\
\hline $\mathrm{K}_{2} \mathrm{O}$ & 0,85 \\
\hline
\end{tabular}

TABEL II: Hasil analisis EDS metakaolin yang digunakan dalam penelitian ini

\begin{tabular}{|c|c|}
\hline Komponer & $\mathrm{wt}(\%)$ \\
\hline $\mathrm{Al}_{2} \mathrm{O}_{3}$ & 34,46 \\
\hline $\mathrm{SiO}_{2}$ & 65,54 \\
\hline
\end{tabular}

Setelah mineral kaolin didehidroksilasi menjadi metakaolin nilai komposisi $\mathrm{SiO}_{2}$ meningkat menjadi 65,54 wt\% dan komposisi $\mathrm{Al}_{2} \mathrm{O}_{3}$ menurun menjadi $34,46 \mathrm{wt} \%$ atau dua komposisi ini memiliki perbandingan 2:1 (Tabel II). Penurunan volume $\mathrm{Al}_{2} \mathrm{O}_{3}$ disebabkan oleh penguapan aluminium pada saat dehidroksilasi.
TABEL III: Hasil analisis EDS dari serat bambu

\begin{tabular}{ll}
\hline \hline Komponen & wt (\%) \\
\hline $\mathrm{Al}_{2} \mathrm{O}_{3}$ & 22,66 \\
$\mathrm{SiO}_{2}$ & 51,11 \\
$\mathrm{Na}_{2} \mathrm{O}$ & 26,24 \\
\hline
\end{tabular}

Gambar 1(b) memperlihatkan morfologi permukaan serat bambu yang digunakan. Terlihat serat bambu memiliki bentuk serabut. Dengan menggunakan fasilitas EDS pada SEM diperoleh komposisi penyusun dari serat bambu adalah seperti yang tertera pada Tabel III.

Tabel III memperlihatkan komposisi kimia serat bambu. Sebagai jenis rerumputan kandungan silika sangat tinggi. Prosentase silika yang tinggi menunjukkan upaya tanaman tersebut melindungi dirinya dari lingkungan [8].

Selanjutnya, Gambar 2 memperlihatkan hasil analisis XRD dari serat bambu digunakan. Pada gambar tersebut terlihat bahwa penyusun dari serat bambu ini adalah $\mathrm{SiO}_{2}$ pada bidang (101) dan $\mathrm{H}_{2} \mathrm{CO}$ pada bidang (110). Hasil yang sama juga 


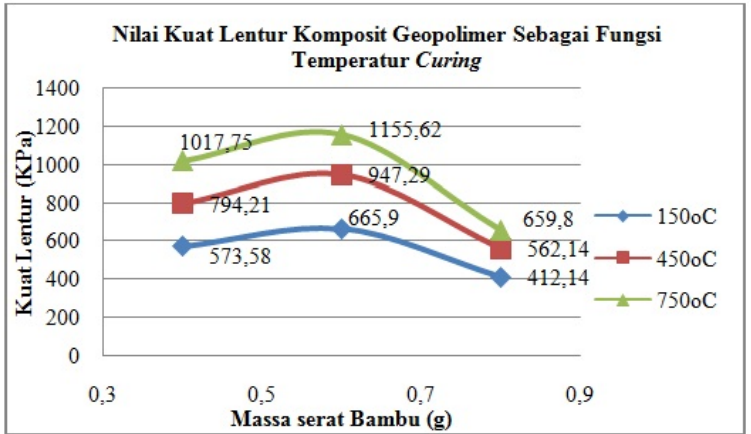

Gambar 3: Kuat lentur komposit geopolimer sebagai fungsi massa serat dan temperatur curing.

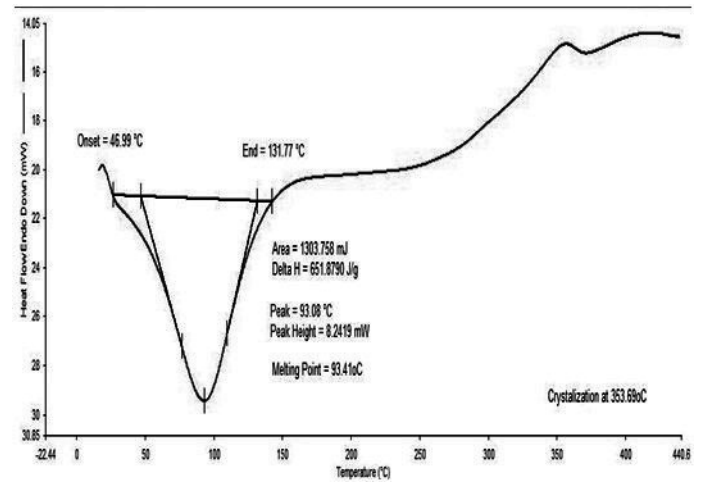

Gambar 4: Hasil analisis DSC serat bambu.

diperoleh oleh Sun [9]. Bidang (101) merupakan puncak difraksi zona amorf dan zona kristal dengan derajat kekrista$\operatorname{lan} 46.27 \%$.

\section{Uji lentur komposit geopolimer}

Kuat lentur komposit geopolimer diukur dengan metode three point bending test. Tujuan dari pengujian kuat lentur ini adalah untuk mengetahui pengaruh massa serat bambu relatif terhadap volume sampel $(0,4,0,6$ dan 0,8 gram $)$ serta temperatur curing $\left(150,450\right.$ dan $\left.750^{\circ} \mathrm{C}\right)$ terhadap kuat lentur sampel.

Hasil pengujian kuat lentur sebagai fungsi massa serat bambu untuk setiap temperatur ditunjukkan Gambar 3. Pada Gambar 3 terlihat bahwa nilai kuat lentur tertinggi diperoleh pada massa serat bambu sebesar 0,6 gram atau $1,5 \%$ dari volume sampel untuk setiap kenaikan temperatur curing. Nilai kuat lentur sampel yang diuji berturut-turut sebesar 665,90 \pm 98,40 KPa, 947,29 \pm 287,13 KPa dan 1152.62 \pm 98,30 KPa.

Hasil analisis termal dari serat bambu seperti yang terlihat pada Gambar 4. Berdasarkan Gambar 4 tersebut dapat diperoleh data perubahan entalpi serat bambu sebesar 651,8790 $\mathrm{J} / \mathrm{g}$ dan bersifat endotermik. Selain itu, diperoleh juga informasi mengenai temperatur kristalisasi serat bambu yakni $353,69^{\circ} \mathrm{C}$. Hal ini menunjukkan bahwa pada temperatur tersebut serat bambu mulai mengkristal sehingga kekuatan mekaniknya ikut meningkat. Hal inilah yang menyebabkan nilai kuat lentur bertambah seiring dengan bertambahnya

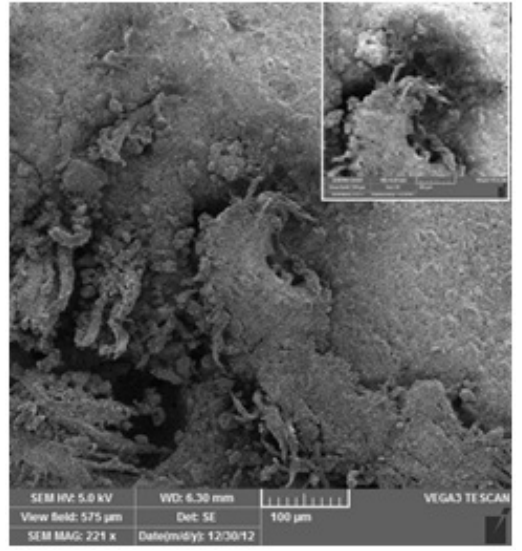

Gambar 5: Morfologi dari komposit geopolimer dengan insert bagian yang diperbesar.

TABEL IV: Hasil analisis EDS komposit geopolimer

\begin{tabular}{lc}
\hline \hline Komponen & wt (\%) \\
\hline $\mathrm{Al}_{2} \mathrm{O}_{3}$ & 39,57 \\
$\mathrm{SiO}_{2}$ & 48,07 \\
$\mathrm{Na}_{2} \mathrm{O}$ & 11,91 \\
$\mathrm{CaO}$ & 0,46 \\
\hline \hline
\end{tabular}

temperatur curing.

Studi tentang kuat lentur juga telah dilakukan oleh Velosa [10]. Hasil penelitian yang diperoleh adalah nilai kuat lentur MK3 memiliki kuat lentur sebesar $700 \mathrm{KPa}$ dan mortar semen sebesar $900 \mathrm{KPa}$. Jika hasil ini dibandingkan dengan nilai kuat lentur komposit geopolimer yang diperoleh memiliki nilai yang lebih baik. Hal ini berarti penguat serat bambu bekerja dengan baik dalam meningkatkan kuat lentur dari sampel.

\section{Struktur mikro komposit geopolimer}

Gambar 5 memperlihatkan morfologi komposit geopolimer berpenguat serat bambu. Tampak adanya celah kosong (void) antara penguat dan matriks. Hal ini dapat berpengaruh terhadap nilai kuat lentur karena menjadi penyebab munculnya retakan (cracks) sehingga komposit akan gagal diawal.

Untuk analisis elemental yang berada pada komposit geopolimer berpenguat serat bambu digunakan fasilitas EDS. Diperoleh $\mathrm{Al}_{2} \mathrm{O}_{3}$ sebesar 39,57 wt $\%, \mathrm{SiO}_{2}$ sebesar 48,07 wt $\%, \mathrm{Na}_{2} \mathrm{O}$ sebesar $11,91 \mathrm{wt} \%$ dan $\mathrm{CaO}$ sebesar 0,46 wt \% lebih lengkap dapat dilihat pada Tabel IV.

\section{SIMPULAN}

Berdasarkan hasil penelitian dapat disimpulkan bahwa penambahan serat bambu sebesar $1,5 \%$ volume sampel $(0,6$ gram) menghasilkan nilai kuat lentur paling tinggi dari komposit geopolimer yang diproduksi, kuat lentur komposit geopolimer merupakan fungsi temperatur curing, hasil karak- 
terisasi mikrostruktur memperlihatkan morfologi komposit

[1] Tonoli, et al., J. Composites: Part A, 40, 2046-2053 (2009).

[2] Subaer dan Abdul Haris, Fisika Material I (Badan Penerbit Universitas Negeri Makassar, Makassar, 2007).

[3] Kamaruddin, et al., Australian Journal of Basic and Applied Sciences, 9, 441-449 (2011).

[4] Zimmermann, et al., J. Advanced Engineering Science, 6(9), 754-761 (2004).

[5] Oksman, et al., Composites Science Technology, 63, 1317-1324 (2003).

[6] E. Dranzfield, E.A. Widjaja, Bamboo (Prosea Foundation, Bo- geopolimer yang belum sempurna. gor, Indonesia, 1995)

[7] Z. Zuhua, et al., J. Applied Clay Science, 43, 218-223 (2009).

[8] W. Fatriasari, Analisis Morfologi Serat dan Sifat Fisis Kimia Beberapa Jenis Bambu sebagai Bahan Baku Pulp dan Kertas, Laporan Teknik Akhir Tahun 2006 UPT BPP Biomaterial, LIPI, 2006.

[9] Sun, et al., Bioresources, 3, 297-315 (2008).

[10] Velosa, et al., J. Acta Geodyn, 153, 121-126 (2009). 